\section{Intra-and intergenotypic competition among commercial eucalyptus clones}

\author{
Bruno Ettore Pavan ${ }^{1 *}$, Rafaela Goularte Amaral ${ }^{1,}$ Rinaldo \\ César de Paula², Bruno Marco de Lima ${ }^{3}$ and Edimar Aparecido \\ Scarpinati ${ }^{4}$
}

\begin{abstract}
Plantations made up of clones carry genetic uniformity that can compromise production. The use of multiclonal plantations is a possible solution. The objective of this study was to identify effects of competition on silvicultural performance of Eucalyptus spp. commercial clones. The experiment was carried out in a randomized block design with 12 eucalyptus clones, three replicates, and five plants per plot. Clones were evaluated for two competition types, intra-and intergenotypic, at 3 and 5 years of age. Competition parameters were estimated based on the analyses performed. Differences were found between the types of competition at both ages for mean annual increment and wood volume. Clones 8 and 9 stood out from the others in both intra- and intergenotypic competition. At 5 years of age, intergenotypic competition produced productivity gains of $13 \%$ in clones 8 and 9 and $4 \%$ overall considering wood volume and mean annual increment.
\end{abstract}

Keywords: Eucalyptus spp., clonal complementarity, selection models.

\section{INTRODUCTION}

The current area of planted forests will not be sufficient to supply growing wood consumption demands. Thus, assessments of productivity and efficiency of species and genotypes on a commercial scale are fundamental. Based on optimistic forecasts, wood demand by 2050 will be 2 billion $\mathrm{m}^{3}$, while production will reach 1.5 billion $\mathrm{m}^{3}$, mainly destined for paper and cellulose, solid wood, and bioenergy production. The largest players in terms of planted forests for industrial purposes are the US, China, and Brazil, and the most cultivated species are Pinus spp. (42\%) and Eucalyptus spp. (26\%) (FSC 2012). In Brazil, Eucalyptus plantations comprised 73\% of 7.84 million hectares in 2016 (IBÁ 2017), distributed across tropical and subtropical regions (Castro et al. 2016).

Appropriate edaphoclimatic conditions, well-established breeding programs, and the development of silvicultural management best practices have contributed to Brazil becoming a world leader in eucalyptus productivity (IBÁ 2017). Elite tree selection and efficient vegetative propagation techniques have brought uniformity to forest plantations, favoring operational management. Currently, most breeding programs incorporate strategies to obtain clones derived from interspecific hybrids, aggregating traits of interest (Assis and Resende 2011). Among the combinations studied, crosses between Eucalyptus grandis and
Crop Breeding and Applied Biotechnology 19: 176-184, 2019 Brazilian Society of Plant Breeding. Printed in Brazil http://dx.doi.org/10.1590/198470332019v19n2a25 \title{
(1)
}


Intra-and intergenotypic competition among commercial eucalyptus clones

Eucalyptus urophylla are of particular interest in terms of yield potential, wood quality, and resistance/tolerance to major diseases and pests (Hodge and Dvorak 2015).

Vegetative propagation was a breakthrough for the Brazilian forestry sector. However, the reduced number of planted clones continues to be widely discussed (Ivetic' et al. 2016). Despite the recommendation that fewer genotypes are economically advantageous (Rezende et al. 2014), the lack of genetic variability can result in losses when plantations cover extensive areas (Castro et al. 2016). Losses can occur from the fact that populations are genetically vulnerable from a phytosanitary standpoint, consequently increasing the incidence and severity of disease and pests (Bruzi et al. 2007, Marcatti et al. 2017).

To disrupt genetic uniformity, the use of mixtures of clones may increase productivity and benefit individuals in the face of biotic and abiotic stresses, due to unknown interactions that occur between genotypes (Martins et al. 2014). These interactions can result in different forms of competition, which have a variable effect on genotype performance, as each genotype has specific competitive capacities (Pavan et al. 2011, Pavan et al. 2014). Competition can be classified as intragenotypic, when it occurs in monoclonal stands, or intergenotypic, when it occurs in polyclonal stands (Perecin et al. 1997).

Competition results from resource division and exists even in monoclonal plantations. In a given location, trees are subject to different microenvironments that vary in terms of sunlight, shading, water availability, soil fertility, and interactions with soil microorganisms (Stape et al. 2010). Trees adjust their morphology in response to competition and resource availability, and competitiveness depends on the relationship between resource acquisition and biomass investment (Donnelly et al. 2016). As such, the positioning of the roots and canopy can offer advantages over neighboring trees (Resende et al. 2016).

Relationships between above- and below-ground characteristics are significantly different among clones, affecting the growth and survival of less productive trees when planted together (Donnelly et al. 2016). According to Donnelly et al. (2016), morphological and physiological differences have implications in predicting gains for high quality clones, which may be under- or overestimated. With experimental management of the structure and genotypic diversity of stands, Boyden et al. (2008) demonstrated that genetic variation reduced the competitive interactions between trees, with implications for both individual and population performance. Thus, the use of clonal mixtures can reduce inherent risks in genetic uniformity and allow greater use of natural resources. In this context, the objective of this study is to identify possible effects of intra- and intergenotypic competition on commercial clones of Eucalyptus spp. at 3 and 5 years of age.

\section{MATERIAL AND METHODS}

The experiment was established in September 2007 by FIBRIA SA in the municipality of Três Lagoas, Mato Grosso

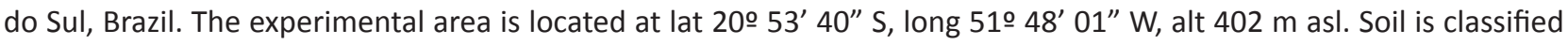
as a Latossolo Vermelho Distrófico with a slope from moderately flat to rolling. According to the Köppen classification, the climate is Aw (tropical with dry winter), with an average annual temperature of $26^{\circ} \mathrm{C}$, relative humidity of $66 \%$, and annual rainfall of $1330 \mathrm{~mm}$ (Centurion 1982).

The competition experiment design was based on the method described by Perecin et al. (1997) which is based on a split-plot design, which enables assessment of genotypes and intra- and intergenotypic competition; genotypes composed the plots and the subplots exhibited competition. According to the examples of the authors, and considering competition among four genotypes $(A, B, C$, and $D)$, each replication must have the same number of genotypes and plots $(A, B, C$, and $D)$. The number of rows $(N R)$ in each plot is calculated as $N R=\{[(n-1) \times 2]+5\}$; where $n$ refers to the number of genotypes. Thus, in a hypothetical example, four plots of 11 rows are necessary, arranged systematically to facilitate visualization (Table 1). The design consists of I) five rows of genotype $i: 1,5,7,9$, and 11, which are considered as neighbors; II) randomly, between these rows (the example is expressed systematically for didactic purposes) are three rows of genotype $i$ (rows 2, 3, and 4), from which the effects of intragenotypic competition will be measured; III) in the remaining rows $(6,8$, and 10$)$, genotype $i$ rows are interspersed with other genotypes, where the effects of intergenotypic competition on genotype $i$ will be evaluated; IV) rows 1 and 11 are experimental plot borders.

In this experiment, 12 commercial hybrid clones of Eucalyptus urophylla $\times$ E. grandis planted by the company were 
BE Pavan et al.

Table 1. Experimental design to test competition among plant genotypes, without randomization and replication

\begin{tabular}{|c|c|c|c|c|c|c|c|c|c|c|c|}
\hline Row Number & 1 & 2 & 3 & 4 & 5 & 6 & 7 & 8 & 9 & 10 & 11 \\
\hline Plot A & A & A & $A$ & $A$ & A & $B$ & A & C & A & $\mathrm{D}$ & $A$ \\
\hline Plot B & B & B & B & B & B & C & B & D & B & $A$ & B \\
\hline Plot C & C & C & $\mathrm{C}$ & $\mathrm{C}$ & C & D & C & A & C & B & C \\
\hline Plot D & D & D & $\mathrm{D}$ & $\mathrm{D}$ & D & A & D & B & D & $\mathrm{C}$ & D \\
\hline
\end{tabular}

evaluated. The experimental design followed the recommendations of Perecin et al. (1997) in a split-plot design. The fixed model and form of statistical analysis was adopted and was arranged with three replications as follows: 12 plots of 27 rows with five plants, spaced at $3.6 \times 2.5 \mathrm{~m}$, for a total of 4,860 individuals in an area of 4.37 ha.

Trees were measured at 3 and 5 years of age. The traits evaluated included tree height $(\mathrm{H}, \mathrm{m})$ and diameter at breast height ( $\mathrm{DBH}, \mathrm{cm}-$ at $1.3 \mathrm{~m}$ from soil level), obtained from $\mathrm{DBH}=(\mathrm{CBH} / \pi)$, where $\mathrm{CBH}$ refers to the circumference at breast height $(\mathrm{cm})$. Wood volume $\left(\mathrm{m}^{3}\right)$ and mean annual increment (MAl, $\mathrm{m}^{3} \mathrm{ha}^{-1}$ year ${ }^{-1}$ ) were obtained based on the calculations provided by the company, considering a form factor per diameter class for each clone tested. For data analysis, average production per row was considered: the surviving trees were measured and the sum divided by the number of trees planted (five per row).

From the data set, effects of intra- and intergenotypic competition at both ages were calculated. Statistical analyses were carried out using the first approach described by Perecin et al. (1997) for general evaluation of intra- and intergenotypic competition within plots. The effect of competition is given in subplots, in which the subplot representing the effects of intragenotypic competition is measured in rows 2, 3, and 4, and the sub-plot representing the effects of intergenotypic competition is measured in rows 5,7 , and 9 (Table 1). In the current experiment, information about intragenotypic competition was obtained from the average of three rows, while intergenotypic competition was evaluated based on the average of 11 rows, considering the following fixed statistical model: $y_{i j k}=\mu+b_{j}+v_{i}+e_{i j}+a_{k}+v_{i} a_{k}+e_{i j k}$, where $y_{i j k}$ is the phenotype of the $i$-th neighbor (plot) of the $j$-th block in the $k$-th subplot; $\mu$ is the overall mean of the experiment; $b_{j}$ is the effect of the $j$-th block; $v_{i}$ is the effect of the $i$-th neighbor (plot); $e_{i j}$ is the interaction effect between the $j$-th block with the $i$-th neighbor (error $a, \hat{\sigma}_{\mathrm{e}_{a}}^{2}$ ); $a_{k}$ is the effect of the $k$-th competitional arrangement (intra- or intergenotypic competition) in the subplot; $+v_{i} a_{k}$ is the interaction effect of competition of the $k$-th subplot with $i$-th neighbor; $e_{i j k}$ is the experimental error associated with observation of the $i$-th neighbor (plot) in the $j$-th block of the $k$-th subplot (error $b, \hat{\sigma}_{\mathrm{e}_{\mathrm{b}}}^{2}$ ).

To verify the significance of the quadratic components $v_{j}, b_{j}$, and $b_{j} v_{i}$ the Snedecor test was used, assessing the significance of the parameters for zero at $5 \%$ probability. Analyses were further developed when the decomposition of the neighboring interactions by competition were significant. Clone (neighbor) averages, as well as the type of competition, either intra- or intergenotypic, and their possible interactions, were grouped using the Scott-Knott test at 5\% probability. From analysis of variance, the following estimates were obtained: $i)$ Coefficient of genotypic variation $\left(\mathrm{CV}_{g^{\prime}} \%\right)$ :

$C V_{g}=\left[\left(\frac{\sqrt{\phi_{g}^{2}}}{\mu}\right) \times 100\right]$, where $\varnothing_{g}^{2}$ refers to the genotypic quadratic component, which expresses the genetic variability of the clones; and $\mu$ is the overall mean of the experiment; ii) Coefficient of competition variation $\left(C V_{c^{\prime}} \%\right): C V_{c}=\left[\left(\frac{\sqrt{\emptyset_{c}^{2}}}{\mu}\right) \times 100\right]$, where $\varnothing_{c}^{2}$ refers to the competition quadratic component, which expresses the competitive variability of the clones.

Experimental coefficients of variation for plots $\left(C V_{a}=\left[\left(\frac{\sqrt{\emptyset_{a}^{2}}}{\mu}\right) \times 100\right],\right)$ and environmental coefficient of variation for subplots $\left(C V_{b}, \%\right): C V_{b}=\left[\left(\frac{\sqrt{\emptyset_{b}^{2}}}{\mu}\right) \times 100\right]$ were obtained. All statistical analyses were performed using the $\mathrm{R}$ software $(\mathrm{R}$ Development Core Team 2016).

\section{RESULTS AND DISCUSSION}

The experiment exhibited good experimental precision at the two ages of evaluation (Table 2), with environmental coefficients of variation lower than has been reported in the literature (Boyden et al. 2008, Nunes et al. 2017). The coefficients ranged from $3.4 \%$ to $6.0 \%$ at 3 years and from $3.6 \%$ to $7.0 \%$ at 5 years, indicating low levels of variation in 
the data at the treatment level in the different replications (Mora and Arriagada 2016). These same authors compared several eucalyptus tests and showed that environmental coefficients of variation $<12 \%$ are considered low, and the inputs in the present study are similar to the minimum found by these authors.

Evaluating E. urophylla $\times$ E. tereticornis hybrid performance at 10 years of age, Chen et al. (2018) observed environmental coefficients of variation from 30 to $43 \%$ for DBH and from 23 to $30 \%$ for height. Evaluating trees at several ages, Li et al. (2017) observed values of environmental coefficients from 11.7 to $23.7 \%$ for height, 13.5 to $26.6 \%$ for DBH, and 31.6 to $53.8 \%$ for wood volume in E. cloesiana progenies. The low environmental coefficients obtained in this study may be related to the use of smaller plots, which can increase the level of competition among individuals (Scarpinati et al. 2009). In previous studies, the effect of competition, which generally reduces the values of environmental coefficients of variation, was not considered. When comparing the values found in this study with values in the literature, the proportions are almost always the same among the traits evaluated, demonstrating that experimental error is minimized when considering the effect of competition.

The VOL and MAI traits had higher environmental coefficients of variation than the other traits. This result is expected since they are based on other variables, such as DBH and H (Scarpinati et al. 2009, Pavan et al. 2011, Pavan et al. 2014, Pupin et al. 2015).

There was a small increase in environmental coefficients of variation at 5 years in relation to 3 years of age, due to the experiment being conducted in the field and to factors that arise with advancing age that cannot be contolled. This results in increased error (Pavan et al. 2014). However, Li et al. (2017) observed divergent results for the traits evaluated; for height, the environmental coefficients of variation decreased with the age of the experiment, whereas for DBH and

Table 2. Summary of analysis of variance for diameter at breast height $(\mathrm{DBH}, \mathrm{cm})$, height $(\mathrm{H}, \mathrm{m})$, wood volume $\left(\mathrm{VOL}, \mathrm{m}^{3}\right.$ tree $\left.{ }^{-1}\right)$, and mean annual increment (MAl, $\mathrm{m}^{3} \mathrm{ha}^{-1}$ year $^{-1}$ ) in Eucalyptus spp. clones at 3 (above) and 5 (below) years of age

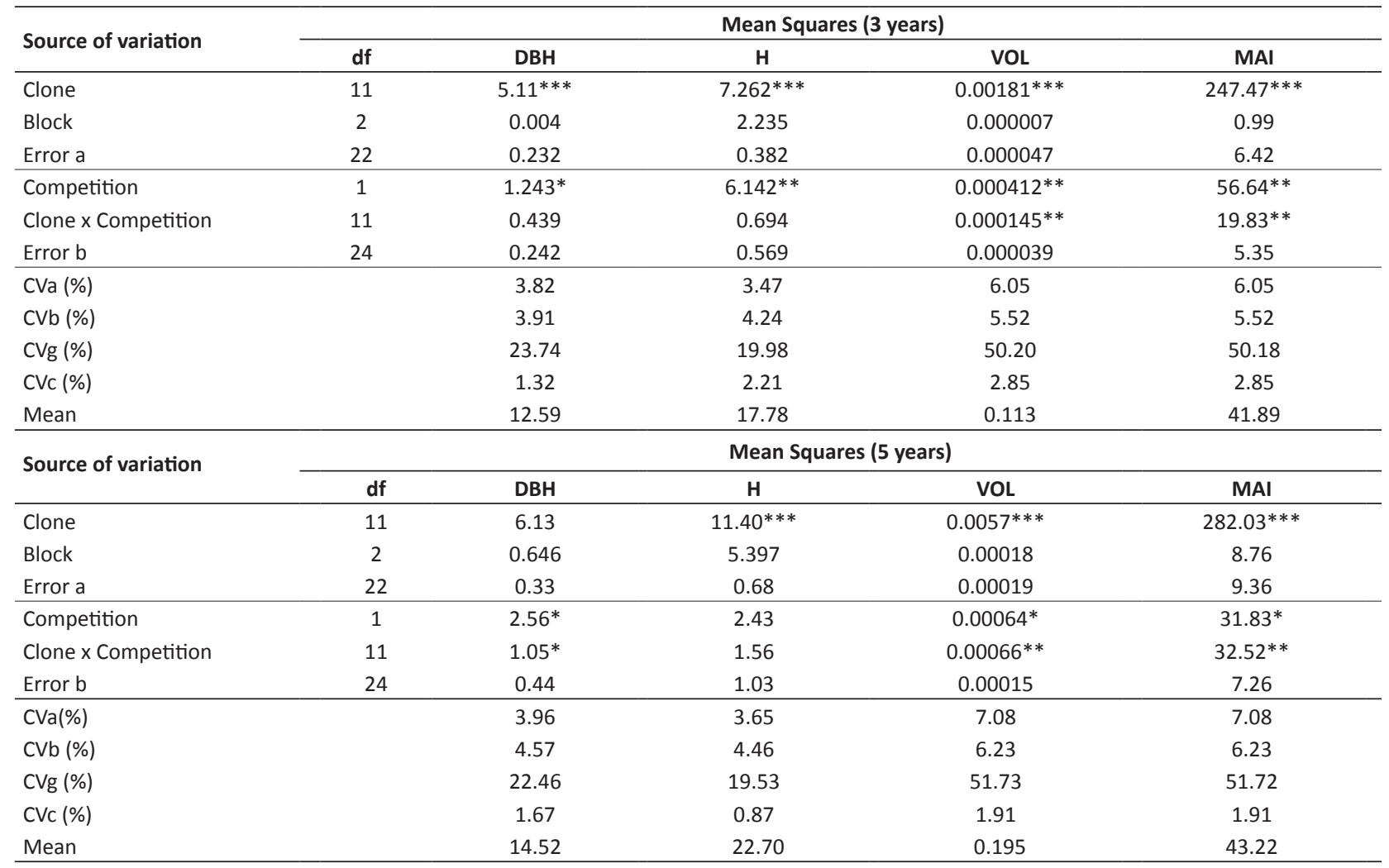

*** significant at $0.001 ; * *$ significant at $0.01 ;{ }^{*}$ significant at 0.05 by the $\mathrm{F}$ test; $\mathrm{CVa}$ : coefficient of variation for plots; CVb: environmental coefficient of variation among subplots; CVg: genetic coefficient of variation; CVc: competition coefficient of variation. 


\section{BE Pavan et al.}

volume, environmental coefficients of variation decreased initially, followed by an increase at more advanced ages, indicating a parabolic response.

Significant differences $(p<0.05)$ were found among clones for all traits evaluated at both ages (Table 2$)$. This reveals the existence of genetic variation among clones, which can enable gains through selection. Furthermore, in principle, the higher the $C V_{g}$ value, the greater the chance of obtaining genetic gains through selection (Kageyama and Vencovsky 1983). $C V_{q}$ ranged from approximately 19 to $51 \%$ among the traits studied, showing high genetic variation. Consequently, VOL and MAI better enable distinctions between clones because they have higher $C V_{g}$ estimates than the other traits studied. Nunes et al. (2017), working with Eucalyptus spp. clones at 3 years of age, obtained $C V_{g}$ values of $8.16 \%$ for $\mathrm{DBH}, 5.09 \%$ for $\mathrm{H}$, and $17.89 \%$ for VOL. Resende et al. (2016), evaluating Eucalyptus spp. clones, found $\mathrm{CV}_{g}$ ranging from 14 to $28 \%$ for MAl. There tend to be higher values of $C V_{g}$ for volume. A similar proportion among traits was observed in this study, which is consistent with previous studies.

Evaluating eucalyptus clones at 3 years of age under three competition schemes, Scarpinati et al. (2009) obtained a $C V_{g}$ for MAl of $6.96 \%, 9.6 \%$, and $15.1 \%$ and observed a tendency toward increased genotypic variance with increased intergenotypic competition. Specifically, smaller experimental plots may favor an increase in the level of distinction among clones. Considering the present study, which was developed with most of the plots showing high levels of competition, distinction among clones was likely favored.

Across the ages studied, a negligible difference was observed among the $C V_{g}$, indicating that selection is possible at 3 and 5 years of age. Engel et al. (2016), evaluating early selection in E. macarthurii, observed genetic correlations above 0.63 among the ages studied, but the correlations at younger ages were lower. Sato et al. (2010) identified high and positive correlations between the ages of 4 and 21 years in C. maculata. For Pavan et al. (2014), the closer the ages were, the higher the positive correlations between ages.

The effect of competition was significant $(p<0.05)$ for all traits evaluated, except for height at 5 years of age. This suggests different behaviors of the clones when affected by intra- or intergenotypic competition and demonstrates changes in the silvicultural performance of a clone when affected by different types of competition; a clone may or may not tolerate the genotypic mixture. Competition has a negative effect on silvicultural performance of clones (Resende et al. 2018), such that, in general, more competitive clones are also more productive, and vice versa (Resende et al. 2016). Progeny tests can result in the selection of competitive ideotypes by the experimental structures adopted in them, and the most competitive materials will not always be the ones with the highest productivity when planted in an equally competitive situation (Martin et al. 2001)

Increase in height is differently affected by the type of competition when the forest has not yet reached the stage of canopy closure, and intergenotypic competition favors this growth earlier than intragenotypic competition (Tables 2,3 , and 4). However, there were no significant effects from the type of competition $(p<0.05)$ on height at 5 years of age, indicating that, once the height of canopy closure is reached, which is determined by the genotype quality of the clone, the predominance of intergenotypic competition on the increase in plant height declines. In contrast, although intragenotypic competition led to important reduction in growth rates initially, this growth was maintained for a longer period of time, at more advanced ages reaching values similar to those of the trees in intergenotypic competition. Thus, intergenotypic competition did not favor growth in height from the middle to the end of the cycle.

Diameter at breast height (DBH) had an inverse reaction to height, in that the mean square of competition doubled from 3 to 5 years, whereas for $\mathrm{H}$, there was a significant reduction. Another parameter that corroborates this finding is the competition coefficient of variation $\left(\mathrm{CV}_{g}\right)$, which increased for $\mathrm{DBH}$ and decreased for $\mathrm{H}$ with advancing age. Once attaining canopy height, plants begin to invest in growth in diameter, which can explain the fact that at 5 years of age, there was no significant effect of competition on height. Therefore, competition has a greater influence on DBH performance of the clones with canopy closure. Wood volume was more affected by intra- than intergenotypic competition, as this trait is calculated based on almost all other measurements (Martins et al. 2014). Thus, for wood volume and MAl, there was an interaction of clones with the level of competition.

At 3 years, the interaction of $\mathrm{DBH}, \mathrm{H}, \mathrm{VOL}$, and $\mathrm{MAl}$ showed that clones had the highest mean values when in intergenotypic competition (Table 3). Some authors studying the effects of competition among Eucalyptus spp. trees 
Intra-and intergenotypic competition among commercial eucalyptus clones

Table 3. Averages for diameter $(\mathrm{DBH}, \mathrm{cm})$ at 3 years and height $(\mathrm{H}, \mathrm{m})$ at 3 and 5 years of age for Eucalyptus spp

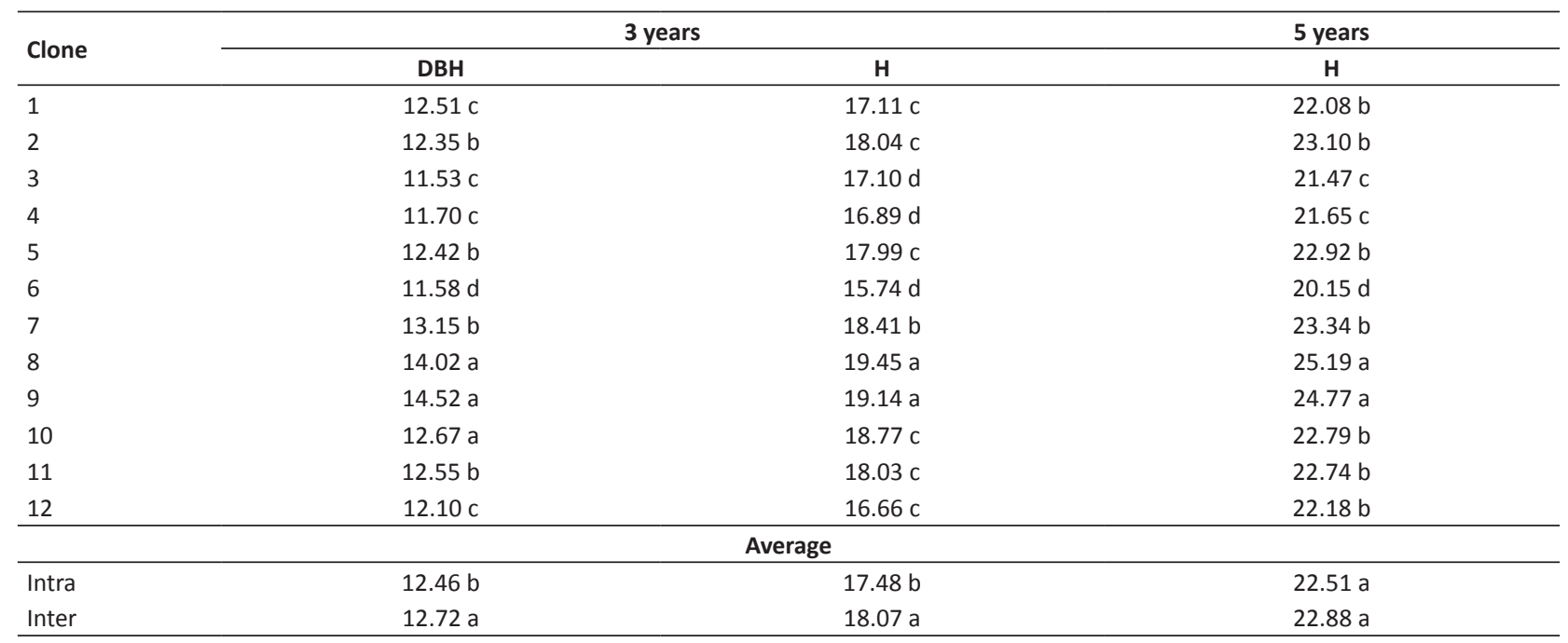

Means followed by the same lowercase letter in the columns and uppercase letter in the lines do not differ statistically, based on the Scott-Knott test at $5 \%$ probability.

have observed that increased genetic homogeneity among individuals reduces growth due to the intensification of competitive interactions for limited resources. Alternatively, plantations with genetically heterogeneous individuals may result in improved sharing of resources as they are better able to exploit the resources available (Chesson 2000, Silvertown 2004, Boyden et al. 2008). Furthermore, differences in growth habit and leaf, branch, and root architecture among clones can promote higher productivity depending on the different needs of the plants (Martins et al. 2014).

All traits were influenced by the level of competition, showing better performance when in intergenotypic competition. For height at 3 years, performance under auto-competition was 17.48 , which is $3.3 \%$ lower than the performance under allo-competition, and for volume, the decrease was $4.2 \%$. However, performance was not the same for all clones. For VOL and MAI, at 3 years, almost all clones obtained better or equal performance in intergenotypic competition than in intragenotypic competition. Therefore, clonal mixtures can be incorporated into planting systems without threatening production; they are also advantageous from an industrial perspective (Martins et al. 2014), not requiring mixtures of different wood densities in the digester. Nevertheless, clone 5 had significantly lower production in intergenotypic competition, while other clones, such as clones 3 and 4 , simply had inferior results. As such, these clones can be classified as mediocre in situations of intragenotypic competition and inferior in the presence of clonal mixtures.

Although clonal mixture is advantageous in general, it may impede the silvicultural performance of particular clones. Choosing clones that adapt to a mixed planting system can offer significant gains in forest production, whereas clones that do not adapt to this new system of planting should be eliminated. Martin et al. (2001) report on the difficulty of finding a single tree ideotype. In this respect, the use of clonal mixtures would allow coverage of a greater number of ideotypes since different clones could coexist. Such ideotypes need to be complementary to each other, resulting in greater overall and individual growth.

At 5 years of age, intergenotypic competition produced a significant increase in clone productivity, as observed through DBH, VOL, and MAI. However, similar to what occurred at 3 years of age for the same clones, competition did not have the same effect on the clones; for some the effect was negative, for others positive. At 5 years, these differences became more evident and thus more significant (Table 4).

Clone 9 differed statistically from the others in both intra- and intergenotypic competition, showing a high competitive capacity. This may result in increases in productivity, since at age 5 , the age at which the experiment was completed, clone 9 had a MAl of $57 \mathrm{~m}^{3} \mathrm{ha}^{-1}$ year ${ }^{-1}$ for intragenotypic competition and $63 \mathrm{~m}^{3} \mathrm{ha}^{-1}$ year ${ }^{-1}$ for intergenotypic competition. Clone 5 at 3 years already showed a limited capacity to tolerate competition, which was confirmed at 5 years of age with a MAI of 42.55 and $36.41 \mathrm{~m}^{3}$ ha $^{-1}$ year $^{-1}$ for intra- and intergenotypic competition, respectively. Clone 4 showed 


\section{BE Pavan et al.}

no differences between means at 3 years; however, at 5 years, the clone had greater performance in intragenotypic competition with a MAI of $39.79 \mathrm{~m}^{3} \mathrm{ha}^{-1}$ year ${ }^{-1}$.

The clones maintained almost the same positions in ranking at the two ages for all traits evaluated. Thus, we can infer that at 3 years of age, the clones already demonstrate the capacity to thrive under or tolerate competition. Some authors have concluded that early evaluation of eucalyptus in Brazil, in the middle of the commercial cycle between 3 and 4 years, may adequately reflect behavior at more advanced ages (Pavan et al. 2014, Castro et al. 2016). However, Soares et al. (2017) observed that heterogeneity of trunk growth increases with advanced age due to individual tree growth capacities and stand competition levels.

By observing the general behavior of the clones, we can infer that the use of genotype mixtures, in principle, did not negatively affect productivity. On the contrary, the use of clone mixtures could increase productivity with appropriate combinations of different densities of wood, providing greater industrial use or even different levels of resistance to pests and disease.

In general, the genotypes exhibited superior behavior in intergenotypic competition; when affected by such competition, there was an increase in productivity of the stand. However, clones 3, 4, 5, and 6, when competing with different genotypes, had lower productivity, with or without significant differences between the types of competition. The best performing genotypes in intragenotypic competition were also better in intergenotypic competition, whereas

Table 4. Averages for diameter ( $\mathrm{DBH}, \mathrm{cm})$, volume (VOL, $\mathrm{m}^{3}$ tree $\left.{ }^{-1}\right)$, and mean annual increment (MAl, $\mathrm{m}^{3} \mathrm{ha}^{-1}$ year $\left.{ }^{-1}\right)$ for Eucalyptus spp. clones at 3 (above) and 5 (below) years of age

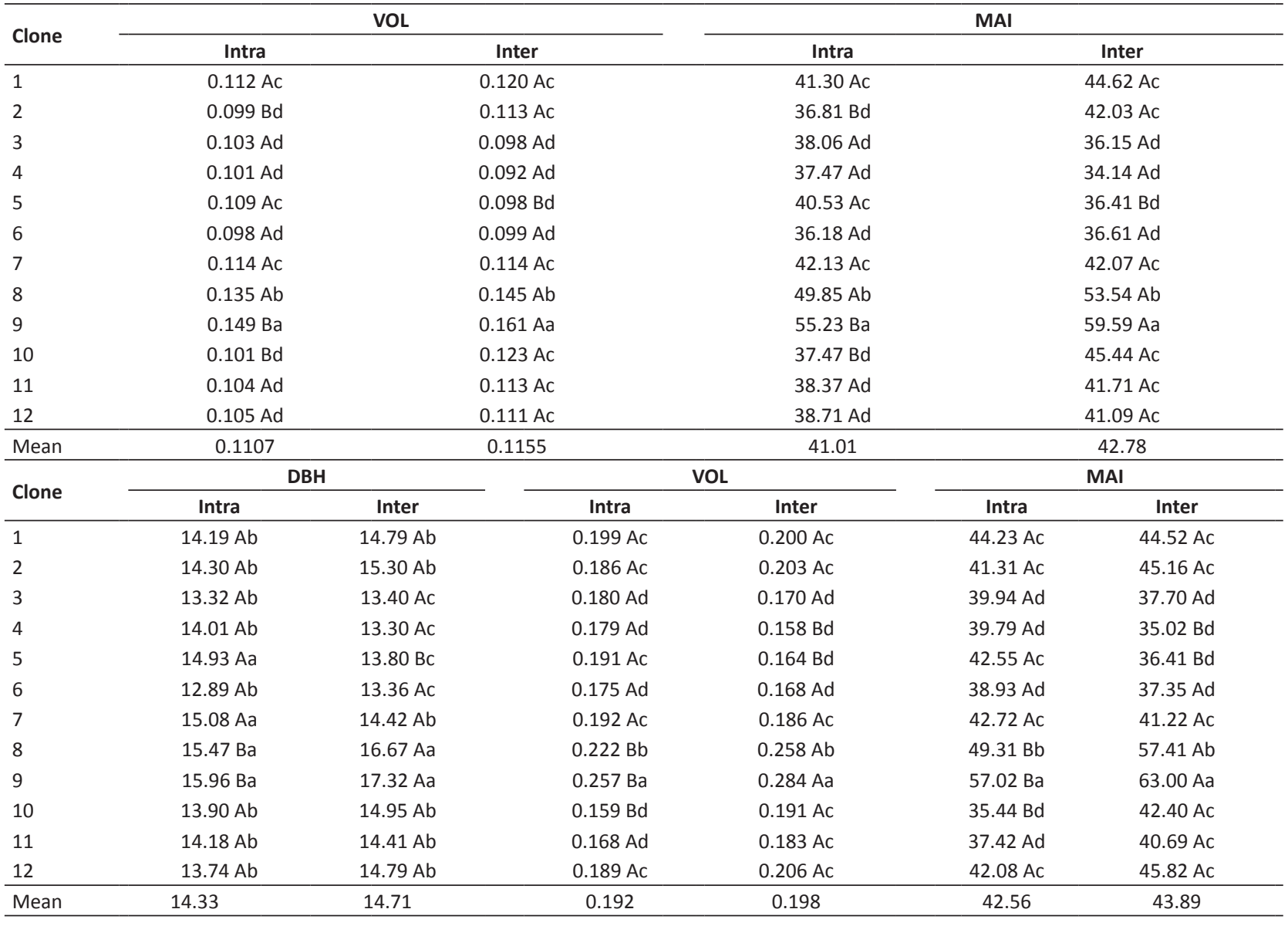

Means followed by the same lowercase letter in the columns and uppercase letter in the lines do not differ statistically, based on the Scott-Knott test at $5 \%$ probability. 
Intra-and intergenotypic competition among commercial eucalyptus clones

the clones with poorer performance did not demonstrate the same behavior. Thus, a genotype considered to be of low performance when under intragenotypic competition can be more productive when interacting with different genotypes. As such, clonal combinations that maximize gains should be employed in plantations in order to obtain an increase in final wood productivity.

\section{CONCLUSION}

The type of competition influenced the behavior of the eucalyptus clones. The general performance in intergenotypic competition favored productivity, but the genotypes differed in their ability to tolerate competition, with some being better able to compete than others. The type of competition does not influence growth in height at more advanced ages or in diameter (DBH) when evaluated at a younger age. Intergenotypic competition may benefit both superior and inferior genotypes, enabling increased productivity.

\section{REFERENCES}

Assis TF and Resende MDV (2011) Genetic improvement of forest tree species. Crop Breeding and Applied Biotechnology 11: 44-49.

Boyden S, Binkley D and Stape JL (2008) Competition among Eucalyptus trees depends on genetic variation and resource supply. Ecology 89: 2850-2859.

Bruzi AT, Ramalho MAP, Abreu ÂDFB, Ferreira DF and Sena MR (2007) Homeostasis in bean population with different genetics structures. Crop Breeding and Applied Biotechnology 7: 111-116.

Castro CAO, Resende RT, Bhering LL and Cruz CD (2016) Brief history of Eucalyptus breeding in Brazil under perspective of biometric advances. Ciência Rural 46: 1585-1593.

Centurion JF (1982) Water balance of the Ilha Solteira region. Cientifica 10: $57-61$.

Chen S, Weng Q, Li F, Li M, Zhou C and GAN S (2018) Genetic parameters for growth and wood chemical properties in Eucalyptus urophylla $\times$ E. tereticornis hybrids. Annals of Forest Science 75: 1-11.

Chesson P (2000) Mechanisms of maintenance of species diversity. Annual Review of Ecology and Sistematycs 31: 343-366.

Donnelly L, Jagodzin' ski AM, Grant OM and O'Reilly C (2016) Aboveand belowground biomass partitioning and fine root morphology in juvenile Sitka spruce clones in monoclonal and polyclonal mixtures. Forest Ecology and Management 373: 17-25.

Engel ML, Higa AR, Andrejow GP, Flôres Jr PC and Soares ID (2016) Genetic gain from different selection methods in Eucalyptus macarthurii progenies in different environments. Cerne 22: 299-308.

FSC - Forest Stewardship Council (2012) Strategic review on the future of forest plantations. Indufor, Helsink, 114p.

Hodge GR and Dvorak WS (2015) Provenance variation and withinprovenance genetic parameters in Eucalyptus urophylla across 125 test sites in Brazil, Colombia, Mexico, South Africa and Venezuela. Tree Genetics \& Genomes 11: 11-57.

IBÁ - Indústria Brasileira de Árvores (2017) Relatório IBÁ 2017. IBÁ, Brasília, 80p.

Ivetic' V, Devetakovic' J, Nonic' M, Stankovic' D and Šijac 'ic'-Nikolic' M
(2016) Genetic diversity and forest reproductive material - from seed source selection to planting. iForest-Biogeosciences 9: 801-812.

Kageyama PY and Vencovsky R (1983) Genetic variation in progenies of a population of Eucalyptus grandis (Hill) Maiden. IPEF 24: 9-26.

Li C, Weng Q, Chen J-B, Li M, Zhou C, Chen S, Zhou W, Guo D, Lu C, Chen J-C, Xiang D and Gan S (2017) Genetic parameters for growth and wood mechanical properties in Eucalyptus cloeziana F. Muell. New Forest 49: 48-33.

Marcatti GE, Resende RT, Resende MDV, Ribeiro CAAS, Santos AR, Cruz JP and Leite HG (2017) GIS-based approach applied to optimizing recommendations of Eucalyptus genotypes. Forest Ecology and Management 392: 144-153.

Martin TA, Johnsen KH and White TL (2001) Ideotype development in southern pines: rationale and strategies for overcoming scale-related obstacles. Forest Science 47: 21-28.

Martins GS, Moura GPL, Ramalho MAP and Gonçalves FMA (2014) Performance of Eucalyptus Clones in auto and allocompetition. Silvae Genetica 63: 9-15.

Mora F and Arriagada O (2016) A classification proposal for coefficients of variation in Eucalyptus experiments involving survival, growth and wood quality variables. Bragantia 75: 263-267.

Nunes ACP, Resende MDV, Santos GA and Alves RS (2017) Evaluation of different selection indices combining Pilodyn penetration and growth performance in Eucalyptus clones. Crop Breeding and Applied Biotechnology 17: 206-2013.

Pavan BE, Paula RC, Perecin D, Candido LS and Scarpinati EA (2011) Minimizing inter-genotypic competition effects to predict genetic values and selection in forestry genetic tests. Scientia Agrícola 68: 671-678.

Pavan BE, Paula RC, Perecin D, Scarpinati EA and Candido LS (2014) Early selection in open-pollinated Eucalyptus families based on competition covariates. Pesquisa Agropecuária Brasileira 49: 483-492.

Perecin D, Malheiros EB, Ferreira JM and Môro JB (1997) Um delineamento para avaliações de auto e alocompetição em plantas Revista de Matemática e Estatística 15: 195-200.

Pupin S, Santos AVA, Zaruma DUG, Miranda AC, Silva PHM, Marino 


\section{BE Pavan et al.}

CL, Sebben AM and Moraes MLT (2015) Productivity, stability and adaptability in open pollination progenies of Eucalyptus urophylla S.T. Blake. Scientia Forestalis 43: 127-134.

R Development Core Team (2016) R: a language and environment for statistical computing. R Foundation for Statistical Computing, Vienna.

Resende RT, Marcatti, GE, Pinto DS, Takahashi EK, Cruz CD and Resende MDV (2016) Intra-genotypic competition of Eucalyptus clones generated by environmental heterogeneity can optimize productivity in forest stands. Forest Ecology and Management 380: 50-58.

Resende RT, Soares AAV, Forrester DI, Marcatti GE, Santos AR, Takahashi EK, Silva FF, Grattapaglia D, Resende MDV and Leite HG (2018) Environmental uniformity, site quality and tree competition interact to determine stand productivity of clonal Eucalyptus. Forest Ecology and Management 410: 76-83.

Rezende GDSP, Resende MDV and Assis TF (2014) Eucalyptus breeding for clonal forestry. In Fenning $T$ (ed) Challenges and opportunities for the world's forests in the 21st century. Springer, New York, p. 393-424.

Sato AS, Freitas MLM, Lima IL, Zimback L, Toniato MTZ and Sebbenn
AM (2010) Genetic variation among and within provenances and progenies of Corymbia maculata (Hook.) K. D. Hill and L. A. S. Johnson, in Pederneiras, SP. Cerne 16: 60-67.

Scarpinati EA, Perecin D, Paula RC, Bonine CAV, Pavan BE and Candido LS (2009) Influences of experimental plot forms and statistical model analysis in Eucalyptus spp clone selections. Revista Árvore 33: 769-776.

Silvertown J (2004) Plant coexistence and the niche. Trends in Ecology and Evolution 19: 605-611.

Soares AAV, Leite HG, Cruz JP and Forrester DI (2017) Development of stand structural heterogeneity and growth dominance in thinned Eucalyptus stands in Brazil. Forest Ecology and Management 384: 339-346.

Stape JL, Binkley D, Ryan MG, Fonseca S, Loos RA, Takahashi EN, Silva CR, Silva SR, Hakamada RE, Ferreira JMA, Lima AMN, Gava JL, Leite FP, Andrade HB, Alves JM, Silva GGC and Azevedo MR (2010) The Brazil eucalyptus potential productivity project: influence of water, nutrients and stand uniformity on wood production. Forest Ecology and Management 259: 1684-1694. 